\title{
O SERVIÇO SOCIAL NA CSS - COORDENADORIA DE SERVIÇOS SOCIAIS CECOM - CENTRO DE SAÚDE DA COMUNIDADE DA UNICAMP
}

Tânia Maria Granzotto ${ }^{1}$

\begin{abstract}
RESUMO
O presente artigo explica a história da CSS - Coordenadoria de Serviços Sociais - CECOM, o qual surgiu em 1982, inicialmente apenas como Ambulatório Médico-odontológico, a clientela, os serviços que abrangia; e o que consiste o serviço hoje, o número de atendimentos e as especialidades que oferece à comunidade universitária. Outro enfoque do texto é a descrição de como é o Serviço Social no CECOM, os objetivos, como é a atuação das assistentes sociais e de que forma isso ocorre.
\end{abstract}

PALAVRAS-CHAVE: Serviço Social; CECOM.

\section{HISTÓRICO}

A Coordenadoria de Serviços Sociais - CSS foi criada através da Portaria GR077/85 em 15/04/1985 pelo reitor José Aristodemo Pinotti. Tinha como objetivo ser o mecanismo administrativo da Administração Superior da Reitoria, destinado a assegurar a execução integrada dos programas e atividades de assistência aos servidores, docentes e alunos da UNICAMP.

Mas a história da Coordenadoria de Serviços Sociais² iniciou em 1982, quando foi implantado o Ambulatório Médico Odontológico da UNICAMP - AMO, que funcionava ao lado do restaurante II para atender os funcionários, docentes e alunos.

\footnotetext{
${ }^{1}$ Assistente Social do CECOM e mestranda na Faculdade de Educação da UNICAMP.

${ }^{2}$ A Coordenadoria de Serviços Sociais - CSS é mais conhecida como CECOM.
} 
Nesta época os serviços sujeitos à coordenação do Ambulatório Médico Odontológico AMO eram: Serviço de Medicina e Segurança do Trabalho, Centro de Convivência Infantil - CECI e Ambulatório de Assistência à Mulher.

Segundo informações do Departamento de Enfermagem do CECOM, em 1984/1985 houve um estudo realizado por uma equipe multiprofissional da área de Saúde Ocupacional da Medicina Preventiva da UNICAMP, onde foi realizado um levantamento das condições de saúde e segurança do campus, o que resultou em uma proposta de criação de um centro de saúde para atender a comunidade universitária, tendo esse estudo sido coordenado pelo Prof. Dr. Renê Mendes ${ }^{3}$. Em decorrência dessa proposta, em 14 de abril de 1986 o reitor José Aristodemo Pinotti, através da portaria GR-095/86 cria o Centro de Saúde da Comunidade da UNICAMP - CECOM, "subordinado à Coordenadoria de Serviços Sociais, destinado a assegurar o planejamento e a execução de programas de atenção à saúde do servidor docente, do técnico-administrativo e do aluno" (UNICAMP..., GR-095/86).

Na época, o CECOM era composto pelos serviços de: odontologia, Assistência integral à saúde da Mulher, Saúde Ocupacional, Saúde do estudante e como apoio o Serviço de Estudos e programas, Administração e o de Enfermagem.

Em 1992 o Centro de Convivência Infantil - CECI se desvincula da CSS, passando a ter vinculação e coordenação técnica administrativa junto à Pró-Reitoria de Extensão e Assuntos Comunitários. Em 2001 o Serviço de Segurança e o Serviço de Medicina do Trabalho também se desvinculam da Coordenadoria de Serviços Sociais CSS.

Atualmente a Coordenadoria de Serviços Sociais - CSS - CECOM é responsável pelo planejamento e execução de programas de saúde a nível preventivo e curativo e

\footnotetext{
${ }^{3}$ Na época docente da área de Saúde Ocupacional da Medicina Preventiva da UNICAMP.
} 
está vinculada diretamente à reitoria da Universidade. Seu objetivo é o atendimento médico-odontológico aos servidores docentes e funcionários (UNICAMP/FUNCAMP), alunos de graduação e pós-graduação, proporcionando uma melhor qualidade de vida aos mesmos através de programas educativos, curativos e assistenciais. A intenção também deste órgão é formalizar como campo de estágio para alunos desta Universidade e outros na área de Saúde Coletiva, colaborando assim com o ensino e a pesquisa.

A Coordenadoria de Serviços Sociais - CSS - CECOM oferece à comunidade universitária o serviço de profissionais nas seguintes áreas: clínica médica, reumatologia, dermatologia, psiquiatria, cardiologia, fisioterapia, psicologia, serviço social odontologia, nutrição, enfermagem, ginecologia, obstetrícia, oftalmologia e acupuntura, atendendo em média 8.700 usuários mês.

\section{O SERVIÇO SOCIAL NA COORDENADORIA DE SERVIÇOS SOCIAIS - CSS - CECOM}

Na esfera do atendimento médico, a atuação do Serviço Social é imprescindível, devendo o assistente social atender às necessidades e problemas sociais dos usuários provocados por conflitos internos e fatores externos. Essa atuação do profissional de Serviço Social ao nível da prática direta poderá ser terapêutica, curativa ou de ajuda, preventiva, promocional ou educativa.

No âmbito da saúde o Serviço Social poderá promover investigações e pesquisas colaborando na identificação dos aspectos sociais das diversas patologias. O assistente social necessita reconhecer a importância do seu envolvimento com investigações e pesquisas científicas para o desenvolvimento profissional e institucional. 


\section{OBJETIVOS DO SERVIÇO SOCIAL DA CSS - CECOM}

- Atuar de forma educativa e de apoio psicossocial junto aos usuários e colaterais, utilizando métodos e técnicas do Serviço Social.

- Interpretar à equipe multiprofissional a situação sócio-econômica e psicossocial dos usuários.

- Prestar orientação previdenciária.

- Contribuir para a remoção de problemas econômicos que possam dificultar o tratamento.

- Participar no planejamento e execução de programas relacionados às diversas patologias.

- Humanizar o atendimento médico.

- Promover a prestação de auxílios concretos.

- Realizar pesquisas do interesse do Serviço Social.

\section{HISTÓRICO DO SERVIÇO SOCIAL}

O Serviço Social na CSS - CECOM teve início em maio de 1989 com uma assistente social, através da iniciativa de uma médica da Saúde Ocupacional para contribuir num levantamento estatístico dos casos de funcionários acidentados do trabalho.

Nesta época o Serviço Social iniciou prestando basicamente auxílios concretos e lutava por um espaço físico, realizando também reuniões para conscientizar os outros profissionais sobre o trabalho que o Serviço Social pretendia desenvolver.

Em 1990 iniciou no setor outra assistente social e pouco depois uma auxiliar social, o que propiciou a realização da jornada de trabalho em turnos de seis horas 
(manhã e tarde), bem como a inserção do assistente social em diversos programas desenvolvidos pelos demais profissionais.

Atualmente o Serviço Social conta com duas assistentes sociais e uma auxiliar social, trabalhando em plantões diários com a prestação de auxílios concretos, orientação psicossocial, previdenciária e outras, além de desenvolver juntamente com a equipe multiprofissional, diversos programas de atendimento grupal, tais como: Grupo de diabetes, Grupo de menopausa, Grupo de hipertensão, Grupo de reeducação alimentar e outros.

O Serviço Social também atua muitas vezes, em parceria com o Serviço de Psicologia da DGRH - Diretoria Geral de Recursos Humanos e com a DAB - Diretoria de Assistência e Benefícios da DGRH, no acompanhamento de servidores docentes e não docentes.

Quanto ao fluxograma, os pacientes chegam ao Serviço Social por procura espontânea, encaminhados pelos demais profissionais do CECOM, através das chefias ou dos diversos setores da Universidade, tendo em torno de 200 usuários como média mensal de atendimentos.

O Serviço Social é subordinado primeiramente à Diretoria Clínica e posteriormente ao coordenador do CECOM, Prof. Dr. Edson Bueno ${ }^{4}$, não havendo interferência destes na atuação dos assistentes sociais nos diversos programas.

\section{ABSTRACT}

That text explains the history of the CSS - Coordenadoria de Serviços Sociais - CECOM, which appeared in 1982, initially hardly medical and odontologic Ambulatory, the patients, the services offered; and the which consist the service now, the number of the appointments and the

\footnotetext{
${ }^{4}$ Professor Assistente Doutor do Departamento de Medicina Preventiva e Social da UNICAMP.
} 
speciality that offer to the universitarian community. The other way of locking the text is the description how social service is in the CECOM, the objetives, how is the actuation of the socials assistant and how happens.

KEYWORDS: Social Work; CECOM

\section{REFERÊNCIAS BIBLIOGRÁFICAS}

UNIVERSIDADE ESTADUAL DE CAMPINAS. Boletim Informativo da Diretoria Geral de Administração da UNICAMP, v. 16, 15 de abril de 1986.

UNIVERSIDADE ESTADUAL DE CAMPINAS. Coordenadoria de Serviços Sociais da UNICAMP. Relatório Quadrienal - 1994-1998.

UNIVERSIDADE ESTADUAL DE CAMPINAS. Portarias da Reitoria. GR-077/85 e GR-095/86.

UNIVERSIDADE ESTADUAL DE CAMPINAS. Coordenadoria de Serviços Sociais da UNICAMP. Proposta da nova estrutura organizacional. 2001.

UNIVERSIDADE ESTADUAL DE CAMPINAS. Coordenadoria de Serviços Sociais da UNICAMP. Relatórios Anuais. 